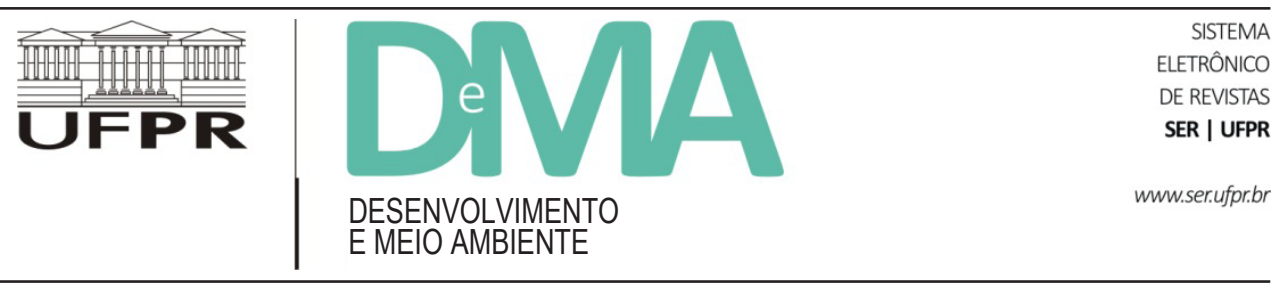

\title{
A emergência da produção de novidades em territórios "marginalizados": uma análise a partir do território Alto Camaquã, Rio Grande do Sul
}

\section{The Emergence of the Novelty Production in "Marginalized" Territories: an Analysis from the Territory Camaquã Alto, Rio Grande do Sul}

\author{
Marcio Zamboni NESKE ${ }^{1 *}$, Flávia Charão MARQUES ${ }^{1}$, Marcos Flávio Silva BORBA² \\ ${ }^{1}$ Universidade Federal do Rio Grande do Sul (UFRGS), Porto Alegre, RS, Brasil. \\ ${ }^{2}$ Empresa Brasileira de Pesquisa Agropecuária (Embrapa), Bagé, RS, Brasil. \\ *E-mail de contato: marcio.neske@yahoo.com.br
}

Artigo recebido em 18 de dezembro de 2013, versão final aceita em 4 de agosto de 2014.

RESUMO Esse artigo analisa a "produção de novidades" no território Alto Camaquã, localizado no sul do Rio Grande do Sul. A abordagem da produção de novidades tem se constituído como um referencial para pensar a inovação e o conhecimento relacionados a processos de desenvolvimento rural. Busca-se evidenciar as respostas diferenciais que os atores sociais são capazes de criar como forma de resistir e/ou de contornar o regime sociotécnico e científico dominante. Demonstra-se que a emergência de processos inovadores, num contexto de valorização e combinação dos recursos e bens locais, são construções que remetem ao diálogo entre diferentes conhecimentos (científicos e tácitos) e à interação entre distintos atores (humanos e não humanos), que se entrelaçam em redes sociotécnicas, constituídas com o objetivo de contestar o regime sociotécnico prevalente e desafiar a narrativa modernizante de desenvolvimento.

Palavras-chave: produção de novidades; redes sociotécnicas; território; pecuária familiar.

ABSTRACT This article examines the 'novelty production' at Alto Camaquã territory, located in Southern Rio Grande do Sul, Brazil. Novelty production approach has been constituted as a framework for thinking innovation and knowledge related to rural development processes. This paper seeks to highlight the differential responses that social actors are able to create as resistance, and also as an opposition to dominant socio-technical and scientific regime. Within a context of recovery and combination of local resources and assets, we show that the emergence of innovative processes results from dialogue between different knowledge (scientific and tacit) and depends on interaction between different actors (humans and non-humans). These latter are intertwined in socio-technical networks, established against the prevalent socio-technical regime, and for challenging the modernizing narrative of development.

Keywords: novelty production; sociotechnical networks; territory; family ranching. 


\section{Introdução}

No campo dos estudos rurais, a temática da modernização da agricultura tem sido, nas últimas décadas, amplamente debatida e analisada quanto aos seus impactos que derivaram num extenso processo de diferenciação social e econômica na agricultura e no mundo rural, bem como os seus efeitos negativos provocados sobre os recursos naturais. $\mathrm{O}$ progresso técnico e a inovação tecnológica constante, enquanto elementos necessários para impulsionar a modernização capitalista na agricultura, foram fortemente condicionados por perspectivas lineares e reducionistas, não levando em consideração as características sociais, econômicas, culturais e ecológicas de cada contexto agrário.

No entanto, mesmo sendo o modelo de agricultura capitalista ainda hegemônico, ele não foi (e não é) um processo homogeneizador, como previam as teorias da modernização. Pois, é em meio a um movimento contestatório no campo epistemológico e teórico da produção do conhecimento e saber que se têm evidenciado as condições responsáveis pela emergência de diferenciadas formas de produção. Formas estas que têm visado à construção de estratégias produtivas mais sustentáveis.

Essa é a condição observada em relação às estratégias de desenvolvimento rural atualmente em curso no território Alto Camaquã, localizado na metade sul do Estado do Rio Grande do Sul. Nele se identificam processos criativos de aprendizagem e geração de novos conhecimentos em um contexto de formação e fortalecimento de redes sociotécnicas envolvendo a ação coletiva da pesquisa, da extensão e pecuaristas familiares. Nesse sentido, novidades têm surgido como "desvios" das lógicas e trajetórias técnico-produtivas lineares oriundas da modernização agrícola, criando possibilidades para gerar estratégias endógenas de desenvolvimento rural que parecem seguir em direção oposta ao regime sociotécnico ${ }^{1}$ dominante da agricultura.

Além dessa parte introdutória, esse artigo está dividido em mais quatro seções. Desse modo, a primeira seção do artigo se dedica a analisar algumas das principais concepções macrossociológicas do desenvolvimento presentes na literatura dos estudos rurais e situar o lugar e o papel da produção de novidades na análise das mudanças sociais. Na segunda seção, a discussão está centrada na apresentação dos antecedentes e dispositivos em que surge a produção de novidades no território Alto Camaquã.

Na terceira seção, discutem-se algumas dessas novidades em "ação", quando se procura demonstrar como as novidades organizacionais e tecnológicas, ao alinharem conhecimentos científicos e tácitos, têm significado respostas e estratégias criativas e sustentáveis de uso e manejo da vegetação campestre envolvendo as práticas coprodutivas dos pecuaristas familiares. Por fim, a quarta e última seção apresenta algumas considerações finais que podem ser úteis para ampliar a reflexão acerca da produção de novidades.

\section{As metamorfoses do desenvolvimento rural: a emergência da produção de novidades na agricultura como contramovimento ao regime sociotécnico dominante}

Ao analisar o curso das transformações do capitalismo agrário, muitas são as questões teóricas, epistemológicas e analíticas que têm reunido elementos que convergem para contestar os impactos e as limitações do modelo de modernização da agricultura implementado a partir da segunda metade do século passado. De certa forma, há um consenso na literatura dos estudos rurais que a modernização da agricultura foi o elemento responsável por acelerar a diferenciação social e econômica no processo de produção agrícola por meio da submissão dessa atividade ao modelo capitalista, caracterizado, sobretudo, pela crescente mercantilização dos fatores de produção e trabalho (Long, 1982; Long \& Ploeg, 2011).

Numa visão clássica, a modernização da agricultura, enquanto um projeto tido como representativo das

\footnotetext{
${ }^{1}$ Segundo Kemp et al. (1998), regime tecnológico representa a gramática ou o conjunto de normas compreendidas no complexo campo de conhecimentos científicos, práticas de engenharia, tecnologias dos processos de produção, formas de definir e resolver problemas, estando tudo isso enraizado em instituições e infraestruturas que constituem a totalidade da tecnologia.
} 
sociedades "modernas", pode ser interpretada como um processo que foi inspirado na ideologia da noção de desenvolvimento como sinônimo de crescimento econômico (Almeida, 1997). A idealização desse processo foi ativada e mantida mediante uma crescente inserção nos mercados e, também, em uma série de intervenções que envolvem a transferência de tecnologia, conhecimento, recursos e formas de organização do mundo dos "mais desenvolvidos" para os "menos desenvolvidos" (Long, 2007). Para Long (1982), a modernização esteve associada a um processo de diferenciação estrutural, ou seja, a modernização denota uma transformação de uma sociedade tida como tradicional ou pré-moderna para uma sociedade adiantada ou moderna.

O desenvolvimento seria, portanto, um processo histórico de mudança social em que sociedades são transformadas ao longo do tempo, representando um esforço consistente e deliberado de determinadas agências, governos e instituições para produzir mudanças (Thomas, 2000). Assim, desde essa perspectiva, a modernização foi uma tentativa universalizante de transformação de sociedades tradicionais em sociedades modernas por meio da homogeneização dos padrões produtivos, saberes culturais e modos de vida das populações rurais.

No entanto, mesmo a retórica do desenvolvimento estando alicerçada na noção de modernidade, o processo de construção de tal retórica não é homogêneo, estando circunscrito no que Arce \& Long (1992) chamam de "campos de batalha do conhecimento"2, pois há interesses diversos nos projetos de desenvolvimento, onde múltiplos atores são confrontados com experiências e valores muitas vezes conflitivos. Por isso, os programas e processos de intervenção ocorrem numa situação de interface social onde diferentes (des)continuidades sociais, modos organizacionais e modos de vida estão presentes. Desse modo, conforme Long (2007), os projetos de desenvolvimento rural são processos socialmente construídos, negociados e processados, onde distintos campos sociais se cruzam. Assim, quando os atores (coletivos ou individuais) portadores de compreensões, culturas e modos de vida específicos fazem "uso comum" das estratégias de intervenção em projetos de desenvolvimento, eles agem (ou deixam de agir) motivados por uma multiplicidade de possibilidades (Long, 2007).

Com isso, mesmo estando os agricultores inseridos num ambiente mercantilizado em que o capitalismo exerce forças de "fora" (tecnologias, sistemas de preço, políticas públicas, etc.), esse processo não transcorre da mesma forma, pois nele mesmo se encontram os espaços de manobra onde os agricultores estabelecem suas estratégias de resistência (Scott, 1987), já que esses possuem capacidades de agência ${ }^{3}$ e habilidades cognitivas para interferir, se necessário, no fluxo de eventos sociais ao seu entorno (Long, 2007). Ou seja, os agricultores, mediante seus repertórios culturais, criam um conjunto de estratégias que acabam desenvolvendo respostas diferenciais em circunstâncias estruturais similares, mesmo se as condições parecerem relativamente homogêneas (Long \& Ploeg, 2011).

Sendo assim, as respostas diferenciais que têm emergido nos espaços rurais como processos de resistência, contestação e/ou mesmo como desconstrução do paradigma produtivista da agricultura acabam sendo criações dos próprios atores (individuais ou coletivos). Trata-se da produção de novidades num ambiente onde se acreditava que a modernização da agricultura seria o único caminho possível para o desenvolvimento do mundo rural.

Nesse sentido, a abordagem da produção de novidades na agricultura tem se constituído nos últimos anos em um importante referencial heurístico para pensar a produção das inovações e do conhecimento, procurando evidenciar as respostas diferenciais que os atores sociais são capazes de criar como forma de resistência, e também como forma "contornar" o regime sociotécnico científico dominante, ancorado nos preceitos da modernização da agricultura. Apesar de ser uma abordagem de origem europeia, os estudos sobre a produção de novidades têm influenciado a comunidade dos estudos rurais brasileiros

\footnotetext{
${ }^{2}$ No original, em inglês, Battlefields of Knowledge.

${ }^{3}$ A noção de agência humana considera a capacidade ou a possibilidade de os atores agirem, pois, segundo Long e Ploeg (2011), os atores sociais são detentores de conhecimentos e capazes de processar a experiência social e de delinear formas de enfrentar a vida, mesmo sob condições extremas de coerção. Essa perspectiva da agência humana é diferente da agência abordada por Latour (2008) e Callon (1986). Mais adiante retomaremos essa questão.
} 
e os esforços recentes, particularmente no sul do Brasil, têm definido uma agenda de pesquisa importante em situações empíricas diversas (Mello, 2009; Marques, 2009; 2011; Oliveira et al., 2011a; 2011b; Gazolla, 2012).

Novidades podem ser compreendidas como novas práticas, artefatos e processos, ou mesmo novos dispositivos organizacionais e/ou arranjos institucionais, que, de alguma forma, acabam alterando rotinas existentes orientadas pelo regime sociotécnico dominante (Ploeg et al., 2004; Oostindie \& Broekhuizen, 2008). Ou seja, novidades emergem no nível de nichos específicos como reação a um determinado regime sociotécnico, o qual corresponde à estrutura de produção dominante.

Desse modo, de acordo com Ploeg (2008), as novidades são "desvios de regras", os quais infringem códigos de condutas legitimados para compreender as coisas. Assim, a produção de novidades faz parte do processo coevolucionário que constitui a própria trajetória da agricultura, na qual, ao longo dos séculos, os agricultores têm introduzido, de propósito ou involuntariamente, mudanças nos processos de produção em cenários geralmente imprevisíveis (Ploeg et al., 2004).

A produção de novidades na agricultura ocupa lugares definidos que seguem uma certa organização que reúne e combina elementos tanto de natureza como de sociedade. Assim, o lugar da produção de novidades é uma rede sociotécnica no sentido atribuído pela teoria do ator rede (Callon, 1986; Latour, 2008), onde atores ${ }^{4}$, de diferentes formas e tamanhos, desempenham papéis de agenciamento ${ }^{5}$ sociotécnico específicos na constituição da rede. Não é possível explicar a emergência de novidades apenas pela ação humana, mas é necessário considerar que há um mesmo estatuto ontológico na constituição e na explicação da realidade, onde humanos e não humanos, simetricamente, se equiparam. Assim, a constituição de uma rede sociotécnica é o efeito de conexões heterogêneas, onde os agenciamentos dos não humanos (natureza, artefatos, artigos, etc.) mobilizam os humanos (pesquisadores, técnicos, agricultores, policy makers) e se complementam com eles, e vice-versa.

Portanto, as redes sociotécnicas envolvendo a produção de novidades constituem um processo altamente localizado, combinando elementos socioculturais, econômicos, institucionais, organizacionais e tecnológicos juntamente com os ecossistemas locais. Por isso, a emergência das novidades está enraizada no local, o que significa que o que emerge num lugar e tempo específico como novidade não necessariamente irá emergir em outra situação (Ploeg et al., 2004).

Essa característica do caráter endógeno da produção de novidades permite distingui-las das inovações. As inovações tecnológicas da agricultura ditas "convencionais" continuam até os dias atuais sendo concebidas exclusivamente por meio do conhecimento dos peritos (cientistas) e, mesmo sendo geradas sem a participação do conhecimento dos leigos (agricultores) ${ }^{6}$, um determinado artefato tecnológico pode ser transferido para outras realidades ${ }^{7}$. Já as novidades, diferentemente, por compreenderem a noção de "processos localizados" e não de "produtos universais", ao emergirem na periferia do regime sociotécnico dominante, acabam sendo o resultado de uma combinação entre conhecimento tácito e conhecimento científico, ainda que estes espaços tenham que ser deliberadamente criados (Ploeg et al., 2004; Ploeg, 2008). Nesse sentido, cabe mencionar o papel e o lugar estratégico que a Agroecologia ocupa atualmente para desenvolver processos de transição no regime sociotécnico no âmbito da produção do conhecimento (baseado no pluralismo epistemológico), dos processos tecnológicos, na construção de circuitos curtos de comercialização e consumo de alimentos ${ }^{8}$.

\footnotetext{
${ }^{4}$ Latour (2001) considera que a palavra “ator" no sentido sociológico se limita a humanos e, dessa forma, toma emprestado da semiótica o termo actante para se referir à simetria existente entre humanos e não humanos.

${ }^{5}$ Callon (1986) usa o termo agenciamento sociotécnico para descrever a diversidade de formas de agência, que não somente a agência humana, mas também a agência dos não humanos.

${ }^{6}$ Ver Guivant (1997) para uma discussão ampliada das relações que atravessam os conhecimentos entre peritos e leigos.

${ }^{7}$ Estes processos estão presentes na teoria da inovação induzida de Hayami e Ruttan (1988) na teoria da eficiência tecnológica de Schultz (1965).

${ }^{8}$ Nesse sentido, cabe mencionar o papel e o lugar estratégico que a Agroecologia ocupa atualmente para desenvolver processos de transição no regime sociotécnico no âmbito da produção do conhecimento (baseado no pluralismo epistemológico), dos processos tecnológicos, na construção de circuitos curtos de comercialização e consumo de alimentos. Ver, por exemplo, Caporal e Costabeber (2000), Gliessman (2000), Altieri (2002), Sevilla-Guzmán (2006), Costa Gomes e Medeiros (2009), Schmitt e Grisa (2013).
} 
Ao "descortinar" novidades que estão "escondidas no local", a produção de novidades desencadeia a transformação e a valorização de recursos disponíveis em territórios específicos, pois permite potencialmente mobilizar recursos e a criatividade que estão subutilizados ou totalmente negados no âmbito dos sistemas convencionais de investigação e intervenção (Oostindie \& Broekhuizen, 2008). Desse modo, como a produção de novidade está fortemente entrelaçada com a endogeneidade, nela mesma se encontram (e não fora dela) as condições necessárias para a construção de vias alternativas de desenvolvimento rural.

\section{Antecedentes e dispositivos de produção de novidades no território Alto Camaquã}

O território Alto Camaquã está localizado na região fisiográfica denominada Serra do Sudeste do Rio Grande do Sul, fazendo parte do Bioma Pampa (Figura 1). Do ponto de vista político-administrativo, pertence à bacia hidrográfica do rio Camaquã, estando localizado no terço superior da mesma. Situam-se nos limites geográficos da bacia hidrográfica do Alto Camaquã partes das áreas dos municípios de Bagé, Caçapava do Sul, Encruzilhada do Sul, Lavras do Sul, Pinheiro Machado, Piratini e Santana da Boa Vista, o que compreende uma área de $8.172 \mathrm{~km}^{2}$ (FEPAM, 2009).

Nesse território, os pecuaristas familiares constituem-se como a principal representação socioprodutiva, sendo que as propriedades rurais com até 50 hectares ocupam $60 \%$ do total de estabelecimentos e apenas $10 \%$ do total da área geográfica dos municípios, o que corresponde a $65 \%$ da população rural local (IBGE, 2006). De tal maneira, muitas das características do contexto socioeconômico, como pequena escala produtiva, produção para subsistência e aspectos culturais (aversão ao risco, "conservadorismo"), mostraram-se incompatíveis às proposições contidas no projeto de modernização (Borba et al., 2009; Neske, 2009).

$\mathrm{Na}$ trajetória do desenvolvimento do capitalismo agrário, as repercussões da modernização da agricultura não tiveram grandes repercussões sobre as formas de produção e trabalho dos pecuaristas familiares. Con-

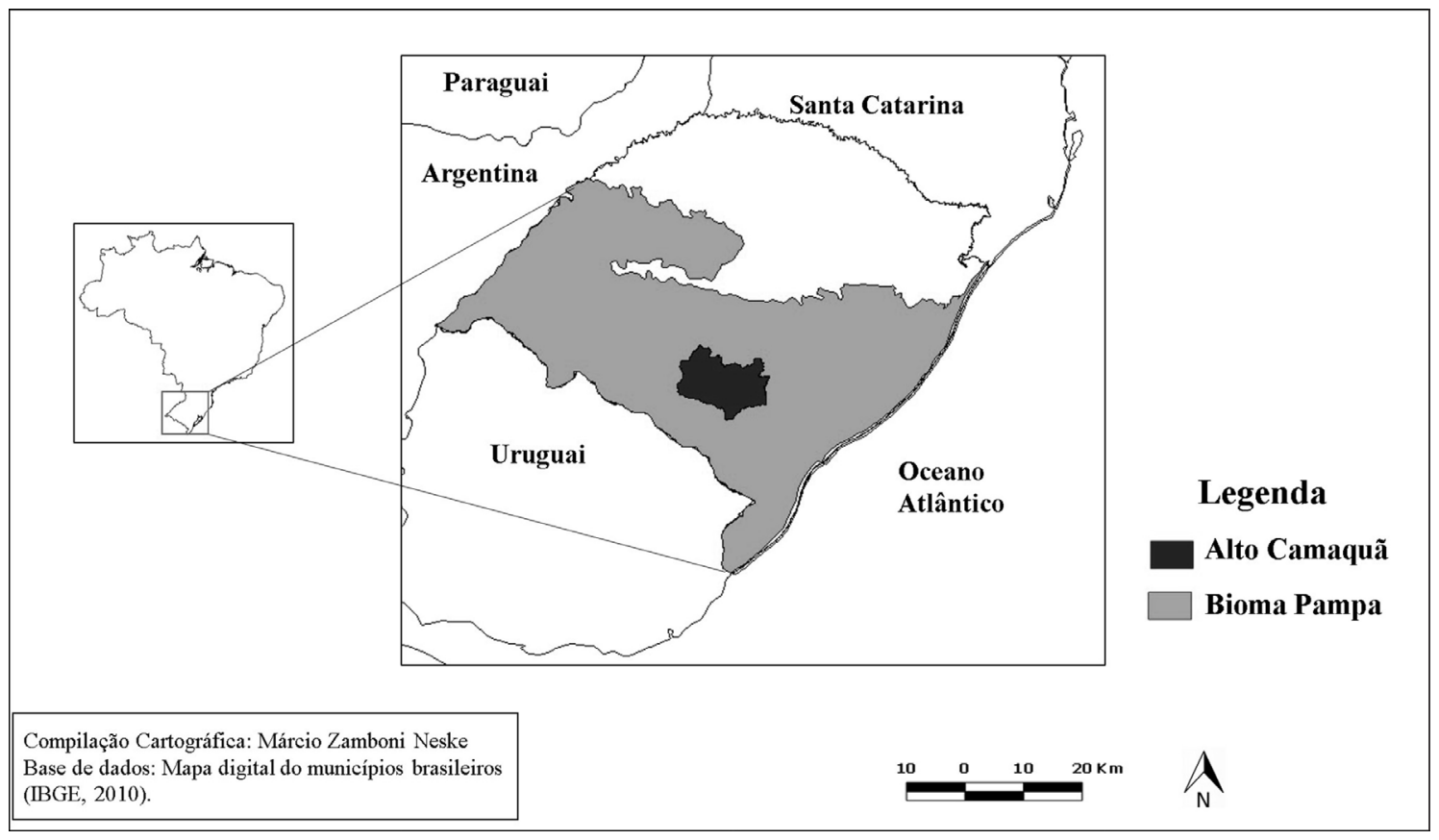

FIGURA 1 - Localização do território Alto Camaquã em relação ao Rio Grande do Sul e ao Brasil. 
forme destaca Borba (2002), a ausência de condições "favoráveis" e necessárias para a transformação produtiva de uma condição de "atraso" à condição "moderna" caracterizou um processo de modernização incompleta dos sistemas produtivos familiares desse território. Esses pecuaristas usam tecnologias relativamente simples e na sua maioria "rudimentares", sendo o principal instrumento de trabalho o "lombo do cavalo", além de ferramentas e equipamentos de uso manual e/ou de tração animal (Neske, 2009). Além disso, a racionalidade produtiva desses pecuaristas não está orientada à maximização dos fatores e recursos produtivos conforme os "manuais" do progresso tecnológico estabelecem.

Assim, analisando o desenvolvimento pelas proposições reducionistas e lineares contidas na teoria de Rostow (1974), a pecuária familiar do Alto Camaquã até os dias atuais mantém características de uma sociedade tradicional ${ }^{9}$. Desse modo, se considerarmos que, conforme a narrativa modernizante, a linha divisória do que é moderno significa a incorporação ipsis litteris de padrões tecnológicos e produtivos proclamados pela modernização agrícola, assim como a crescente inserção nos mercados agrícolas, a pecuária familiar é uma atividade produtiva com características "pré-modernas".

Porém, a não adoção de modelos produtivos modernos tem levado à estigmatização dos pecuaristas familiares, conforme ponderam Borba e Trindade (2009), sendo considerados como "ineficientes" e "atrasados" justamente por se manterem distanciados dos padrões técnico-produtivos propostos. Pela narrativa moderna, esse atraso tecnológico, evidentemente, é considerado um problema a ser resolvido, pois estar-se-ia tratando de uma atividade produtiva que tem sido refratária à inovação tecnológica e produtiva.
As promessas do progresso imbuídas da ideia moderna de ciência e tecnologia ainda se mostram potentes para legitimar retóricas e regimes de ação como princípio de ordenação das estratégias de desenvolvimento no Alto Camaquã, sobretudo quando se imagina que o progresso técnico-científico tem um papel importante a cumprir para a completitude do progresso econômico que ainda não foi possível. Especialmente na última década, a estrutura produtiva do Alto Camaquã tem sido alterada e áreas historicamente ocupadas pela atividade pastoril da pecuária de corte têm cedido espaço para outras atividades.

Entre essas atividades está o plantio de eucalipto que, a partir de 2005-2006, recebeu amplos investimentos $^{10}$, além da expansão do plantio de soja que, no período de 2000-2011, teve um aumento de $768 \%$ na área plantada (IBGE, 2011). Assim, a retórica da concepção de desenvolvimento que tem direcionando ações de intervenção para o desenvolvimento do Alto Camaquã tem posicionado os pecuaristas familiares como pertencentes a um movimento histórico que tem considerado esse território como sendo socioeconomicamente "subdesenvolvido"11.

Desse modo, a consonância de que o Alto Camaquã é um território improdutivo e deprimido economicamente, por um lado, tem facilitado a permanência de um discurso produtivista top down, e, por outro, é no interior da matriz institucional e organizacional legitimadora da narrativa modernizante que têm emergido processos contestatórios. Outros significados e interesses em torno das noções de desenvolvimento têm questionado e confrontado a narrativa modernizante do desenvolvimento e loci de enunciações têm surgido renunciando, ressignificando e traduzindo os signos dessa narrativa moderna,

\footnotetext{
${ }^{9}$ Nas etapas do desenvolvimento econômico de Rostow (1974), a sociedade tradicional representa o primeiro estágio do desenvolvimento. Para Rostow, a sociedade tradicional é aquela em que o nível de produção per capita é limitado, devido à baixa produtividade ocasionada principalmente pela falta de tecnologia. Nessa sociedade, portanto, a maior parte das atividades produtivas está ligada à produção agrícola.

${ }^{10}$ Não existem dados estatísticos oficiais a respeito do tamanho da área plantada com eucalipto na região, mas alguns impactos socioeconômicos e ambientais decorrentes do plantio de eucalipto podem ser encontrados nos estudos de Neske (2009) e Matte (2013).

${ }^{11}$ Existe uma tradição dos estudos sobre o desenvolvimento econômico no Rio Grande do Sul preocupada em oferecer respostas que expliquem as diferenças do desenvolvimento entre as regiões no Estado. As explicações baseadas em indicadores econômicos (PIB, Renda, Valor Agregado, etc.) conduziram a criação de uma geopolítica do desenvolvimento que divide o Estado em duas metades: uma metade norte rica e desenvolvida (eixo norte/nordeste) e uma metade sul pobre e subdesenvolvida. As explicações para a pobreza da metade sul, onde se encontra o Alto Camaquã, se deve ao fato de que até os dias atuais é uma região com pouco dinamismo econômico, tendo em vista que sua estrutura produtiva se consolidou no período colonial com a atividade da pecuária de corte e pouco se alterou ao longo do tempo (Bandeira, 1994; Alonso, 2006; Rocha, 2011). Evidentemente, não concordamos com essa perspectiva de desenvolvimento e, para uma análise crítica, ver Neske et al. (2013).
} 
de outros modos, em narrativas "descolonizantes" de defesa e valorização do local.

Sob esse aspecto, a partir dos anos 2000 foi iniciado um conjunto de ações de pesquisa e extensão rural direcionadas à pecuária familiar, sendo esses trabalhos conduzidos conjuntamente e/ou paralelamente pelas empresas locais de pesquisa agropecuária (Embrapa $)^{12}$ e extensão rural (Emater/RS) ${ }^{13}$. A gênese desse processo está associada ao fato de que existia um contingente significativo de formas familiares de produção ignoradas ou pouco assistidas pelos órgãos de pesquisa, extensão rural e, principalmente, pelas políticas públicas.

Por outro lado, a ideia era buscar a possibilidade de desencadear um processo de renovação das abordagens de trabalho dessas organizações, evitando estratégias de intervenção social e técnica clássicas. Ou seja, seguindo prioridades estabelecidas a priori no interior das organizações, normalmente orientadas para a busca da modernização dos pecuaristas familiares.

Fundamentalmente, esses trabalhos visavam a uma aproximação dessas organizações com o contexto social dos pecuaristas familiares de forma a obter conhecimentos sobre os processos socioeconômicos e produtivos de uma categoria social que, até então, pouco se conhecia. As atividades de trabalho foram conduzidas por um grupo de pesquisadores e técnicos que buscavam a criação de algum "espaço de manobra" no interior das suas organizações, procurando possibilidades diferenciadas de atuação.

O investimento nesses trabalhos iniciais proporcionou a pesquisadores e técnicos a obtenção de uma representação da heterogeneidade e diversidade das práticas e processos produtivos dos pecuaristas familiares, assim como dos conhecimentos e lógicas que orientam um modo de vida bastante particularizado. Esse acúmulo inicial permitiu um reordenamento importante das ações de pesquisa e extensão rural. Os pecuaristas familiares foram ganhando "porta-vozes" que passaram a lhes representar e aos poucos passaram a sair do "anonimato".

Assim, a partir dessas experiências iniciais das ações de pesquisa e extensão, precisamente no ano de 2008, teve início o Projeto Alto Camaquã (PAC), sendo concebido desde uma abordagem territorial para pensar e promover estratégias de desenvolvimento no território. Não se trata de um projeto de pesquisa, como o nome pode sugerir, mas de um movimento de ação coletiva de atores locais que tem representado um processo de resistência contrária às práticas desenvolvimentistas que se intensificaram no Alto Camaquã nos últimos anos. O Projeto prevê ações de intervenção que visam "redescobrir" e "revalorizar" o local como portador de experiências e elementos socioeconômicos, culturais e ambientais próprios capazes de gerar e dar suporte a estratégias endógenas de desenvolvimento rural (Borba $\&$ Trindade, 2009) $)^{14}$. Fundamentalmente, o Projeto Alto Camaquã tem renunciado à visão estigmatizada de atraso e improdutividade dos sistemas produtivos familiares, procurando atribuir valor aos ativos (culturais, naturais, sociais, econômicos) que sempre fizeram parte da história local.

Em meio às concepções hegemônicas de pesquisa e extensão até então consagradas, essas ações de pesquisa e extensão têm representado "práticas desviantes", uma vez que estabelecem novas regras, normas e processos de atuação que têm se diferenciado das rotinas da produção de conhecimentos institucionalizadas. Se a trajetória institucional da Embrapa e Emater envolveu (e envolve) compromissos com a modernização tecnológica, levando à marginalização de conhecimentos tradicionais e à tentativa de mudança de tecnologias

\footnotetext{
${ }^{12}$ Empresa Brasileira de Pesquisa Agropecuária que mantém uma unidade de pesquisa em Bagé, o Centro de Pesquisa Pecuária Sul, o qual tem abrangência regional.

${ }^{13}$ Associação Sulina de Crédito e Assistência Rural - ASCAR/RS, entidade oficial de extensão rural no Rio Grande do Sul. Opera no Alto Camaquã com escritórios municipais e dois escritórios regionais, com sedes em Bagé e Pelotas.

${ }^{14}$ Essas proposições constituintes do PAC são partícipes do que a literatura tem definido como abordagem territorial do desenvolvimento. No caso do Brasil, a abordagem territorial do desenvolvimento passou a ganhar centralidade nos estudos rurais nos últimos 15 anos e, de modo geral, autores como Abramovay (2000), Favareto (2007), Saquet (2007) e Schneider (2009) afirmam que pensar o território desde a abordagem do desenvolvimento significa compreendê-lo a partir de quatro elementos principais: a) as relações de poder; b) as redes sociais e econômicas de circulação e comunicação; c) as identidades; d) a natureza. Assim, pensar o desenvolvimento pela abordagem territorial requer a consideração destes elementos em cada território.
} 
"tradicionais" para a aplicação de tecnologias modernas baseadas no conhecimento científico, o que está em jogo com o Projeto Alto Camaquã é a criação das condições de possibilidades para promover mudanças dos pontos de vista epistemológico e metodológico em processos sobre a geração de conhecimento.

É na interface entre atores heterogêneos do Projeto Alto Camaquã que se verificam processos emergentes de desobediências epistêmicas, onde atores individuais têm revisado não somente o papel de atuação dos dispositivos político-organizacionais-institucionais a que pertencem, mas também, e sobretudo, se verifica a criação de novas formas de ordenação e atuação desses dispositivos em apoio aos pecuaristas familiares e à valorização do lugar. $\mathrm{O}$ que faz, então, os atores reposicionarem suas formas de atuação? Nesse sentido, é importante destacar as trajetórias de vida individuais que definem e são definidas por um imperativo de justificação situacional que sustenta e coordena a conduta dos indivíduos (Boltanski \& Thevenot, 1999) que, associado à correlativa liberdade de pensamento e à capacidade crítica e reflexiva dos indivíduos, os leva a definir outras formas de compreensão e retóricas do desenvolvimento.

Desse modo, rotinas existentes passaram a ser alteradas no interior das organizações de pesquisa e extensão e passaram a emergir, então, nesse momento, as condições para a produção de novidades organizacionais em relação à construção de projetos de pesquisas técnico-científicas direcionadas à pecuária familiar do Alto Camaquã. $\mathrm{O}$ Projeto Alto Camaquã é, então, ele próprio, uma novidade institucional que interliga uma rede de multiatores, como centros de pesquisa (Embrapa) e extensão rural (Emater), universidades, associações de produtores (21 associações que correspondem a 400 famílias), representações sindicais (FETAG, Sindicatos dos Trabalhadores Rurais), governos municipal e estadual (por intermédio da Secretária de Desenvolvimento Rural - SDR).

A produção de novidades é estruturada e opera na forma de redes sociotécnicas e, ao mesmo tempo, é a partir delas que outras novidades inesperadas surgem. Segundo Ploeg (2008), as novidades são encadeadas por meio de redes, pois frequentemente se desenvolvem em direções inesperadas, onde novidades isoladas ou desconhecidas passam a ser consolidadas. Nesse sentido, Ploeg (2008) demonstra a interligação de novidades citando como exemplo o caso da cooperativa holandesa das Florestas do Norte da Frísia (FNF), onde uma novidade tecnológica inicial, o "estrume bom", desencadeou o surgimento de outras novidades inesperadas, como novidades tecnológicas, produtivas e organizacionais.

Lançando mão da abordagem de redes sociotécnicas, que sugere que agentes humanos e não humanos assumem identidades de acordo com a sua estratégia de interação, identificam-se comportamentos e processos imprevistos, que provocam a emergência contínua de novidades no Alto Camaquã. Aqui, se está considerando como inicial da novidade organizacional que envolveu diferentes organizações para a geração diferenciada de conhecimento, como anteriormente comentado. A partir dela, outras novidades organizacionais importantes surgiram, como a criação da Associação para o Desenvolvimento Sustentável do Alto Camaquã (ADAC), da Rede de Produtores e Empreendedores do Alto Camaquã (REAC) e da Feira Alto Camaquã. Também destaca-se o surgimento de uma novidade institucional importante, a criação do Fórum do Alto Camaquã, o qual representa o principal espaço de governança local. Trata-se de um espaço coletivo de discussão entre diferentes atores locais para o planejamento de ações de desenvolvimento.

Na constituição da rede sociotécnica que interliga as novidades relacionadas ao Projeto Alto Camaquã, identifica-se um ator mundo, que é aquele que inicia a construção de uma rede e realiza as principais operações de tradução ${ }^{15}$ (Callon, 1986), no caso, o Labeco ${ }^{16}$. É a partir dele que se estabelecem ligações importantes no interior do projeto, que acabam por orientar as ações de desenvolvimento no território.

\footnotetext{
${ }^{15}$ Segundo Callon (1986), traduzir é estabelecer-se como um porta-voz, exprimindo em sua própria linguagem o que os outros dizem e querem, como agem e como se associam uns aos outros. A tradução também envolve a ideia de negociação e deslocamento de interesses, onde os actantes negociam, modificam e deslocam seus vários e contraditórios interesses (Callon, 1986; Latour, 2000; 2001).

${ }^{16}$ Laboratório de Estudos em Agroecologia e Recursos Naturais pertencente ao centro de pesquisa da Embrapa Pecuária Sul, localizado no município de Bagé-RS.
} 
Muitos são os resultados das ligações estabelecidas pela ação deste ator mundo e se podem destacar algumas novidades tecnológicas, como é o caso das Unidades Experimentais Participativas (UEPAs); novidades produtivas, representadas por processos de diferenciação e qualificação de produtos (carnes, produtos agroindustriais, artesanato e turismo); novidades de mercado, bem representadas pela criação da marca coletiva "Alto Camaquã", que visa à certificação participativa dos produtos do território e à venda coletiva de produtos.

Interessante apontar que a estabilização de novidades é potencialmente capaz de promover a emergência de espaços institucionalmente protegidos (nichos de inovação), no entanto, esse é um processo que será tanto mais efetivo quanto mais os atores envolvidos forem capazes de legitimar aprendizagens múltiplas por meio da construção de consensos e compromissos (Marques, 2009). Assim, o Projeto Alto Camaquã é a principal novidade do território, mas também é uma rede sociotécnica constituída por outras redes de novidades interligadas, as quais continuamente têm sido responsáveis por desencadear a construção de princípios comuns em relação à concepção de valores locais sobre o desenvolvimento anteriormente inexistentes nesse território.

\section{Novidades organizacionais e tecnológicas em ação no Alto Camaquã: uma análise das unidades experimentais participativas (UEPAs) ${ }^{17}$}

Uma característica importante a ser destacada em relação à cobertura da vegetação do Alto Camaquã é que o perfil dessa vegetação se caracteriza pelo predomínio de mosaicos campo/formações herbáceo-arbustivas e floresta nativa (Trindade et al., 2010), o que envolve práticas e conhecimentos bastante particularizados de uso e manejo da vegetação campestre ${ }^{18}$ pelos pecuaristas. Então, seria possível indagar: trata-se de uma pecuária que é realizada em "campo sujo", conforme a expressão usada pelos pecuaristas para se referir à vegetação campestre? Sim, exatamente isso. O "campo sujo" é o campo que oferece a base da alimentação para os animais, não sendo constituído apenas por espécies forrageiras, mas por diferentes padrões de vegetação que incluem espécies herbáceas, arbustivas e florestais.

Se adotada uma concepção convencional, produzir em "campo sujo" é um problema que precisa ser erradicado. Desse ponto de vista, os esforços deveriam ser no sentido da uniformização e da busca de alta produtividade, superando as possíveis condições naturais desfavoráveis pelo uso de tecnologias modernas, uma vez que a ideia generalizada é de que não é possível obter rendimentos produtivos e ganhos econômicos satisfatórios em situações não ideais.

Mas então, como domesticar uma natureza que é "selvagem" e tornar a produção pecuária produtiva? Para os problemas formulados com esse tipo de pergunta, o progresso técnico-científico tem apresentado soluções convencionais. No norte do país, por exemplo, no bioma Amazônia, a pecuária avança sobre a floresta pelo uso de práticas de desmatamento, deixando impactos irreparáveis; na região centro-oeste, a pecuária avança sobre o bioma Cerrado do mesmo modo; e, no Rio Grande do Sul, na intenção de aumentar a produtividade da pastagem natural, os campos do bioma Pampa têm cedido espaço para poucas espécies cultivadas ou para a integração lavoura-pecuária ${ }^{19}$.

O questionamento anterior certamente não faz sentido para os pecuaristas familiares, pois para eles não se trata de domesticar uma natureza "selvagem", o que está em jogo é a criação de espaços de convivência dentro de limites que são estabelecidos entre homem e natureza. Essa condição tem se mantido ao longo do tempo devido a um processo coevolucionário estabelecido entre homem e natureza, no qual a cultura local, consolidada por meio da atividade pastoril, ao se adaptar às condições naturais, vem sendo responsável pela manutenção e pela conservação dos campos naturais (Borba \& Trindade,

\footnotetext{
${ }^{17}$ As entrevistas citadas nessa seção foram realizadas pelo primeiro autor no segundo semestre de 2012.

${ }^{18}$ Quando falamos em vegetação campestre, estamos nos referindo ao tipo específico de vegetação que serve de alimentação para os animais.

${ }^{19}$ De acordo com o Ministério do Meio Ambiente (2010), a supressão da vegetação nativa do bioma Pampa provocada pela reconversão produtiva atinge $54 \%$ da área original de $177.767 \mathrm{~km}^{2}$. Entre o período de 2002 e 2008, o bioma Pampa contabilizou uma perda de 251.400 hectares de vegetação nativa.
} 
2009). Portanto, as perguntas "convencionais" formuladas pelos experts em relação ao que é um problema de pesquisa que precisa ser solucionado certamente não são as mesmas perguntas e, tampouco, as respostas elaboradas pelos pecuaristas familiares.

Assim, nas formas de uso da terra onde a vegetação campestre representa o principal recurso forrageiro de alimentação dos animais, o excesso de "mato", à primeira vista, parece ser um problema que impõe limitações ao processo produtivo. No entanto, são os próprios pecuaristas familiares que demonstram, por meio de seus conhecimentos tácitos, o nível de intervenção com o qual devem ser manejadas as áreas, visando conciliar a produção (desde uma racionalidade econômica específica) e a manutenção de uma base de recursos naturais (Neske et al., 2012).

No entanto, os processos produtivos da pecuária familiar têm sido associados a uma produção de baixa eficiência, com rendimentos inexpressivos, sendo esses fatores interpretados na visão convencional da pesquisa e extensão rural, também, como consequência do manejo "inadequado" ${ }^{20}$ exercido pelos produtores sobre a vegetação campestre. Ou seja, parte-se do princípio que rendimentos satisfatórios da produção pecuária requerem um "bom" manejo da vegetação campestre, seguindo orientações técnico-produtivas comprovadas cientificamente.

Essa "visão" é herdeira do paradigma científico cartesiano, onde o pesquisador, ao intervir em situações controladas e não em situações da realidade social, considera que o único resultado válido é a eficiência produtiva, culminada com a combinação entre taxas elevadas de crescimento das pastagens e o maior desempenho animal. Essa conduta, associada à especialização do conhecimento, gera uma situação na qual a maior parte dos cientistas tem dificuldades em lidar com sistemas complexos, que combinam elementos naturais e sociais, humanos e não humanos. Com isto, a complexidade de um determinado sistema social-natural é reduzida, passando a ser estudada isolando-se alguns fragmentos do sistema natural (animais, solo, plantas, etc.) para estudo, de preferência em condições controladas, como campos experimentais e laboratórios.

Portanto, historicamente o conhecimento técnico-científico produzido a respeito do manejo da vegetação campestre tem sido armazenado em caixas-pretas ${ }^{21}$, onde somente o pesquisador ou a comunidade científica possui a chave que decodifica o conhecimento que se encontra dentro dela. Os estudos científicos sobre pastagens naturais no Rio Grande do Sul consagram uma longa tradição de pesquisa, que remonta aos últimos 50-60 anos, em centros universitários e empresas públicas de pesquisa ${ }^{22}$, no entanto, pouco dialogam com os conhecimentos dos pecuaristas familiares.

Essa postura epistemológica e metodológica da produção do conhecimento é reveladora de um processo onde os agentes do desenvolvimento não atuam como elo entre mundos diferenciados, pois eles próprios constroem as representações dos mundos sociais que pretendem interligar e o campo de relações que torna possível este modo específico de interligação (Neves, 2008). Segundo Sardan (1995), na maior parte dos casos os agentes do desenvolvimento não "aprenderam" a ser mediadores entre dois sistemas de conhecimentos, devido ao fato de que as suas competências técnicas foram construídas sobre uma denegação e uma rejeição dos conhecimentos dos agricultores.

Nas diferenciações entre os conhecimentos de peritos (cientista) e leigos (agricultor), os peritos constroem "áreas de ignorância" que perpetuam a superioridade do seu conhecimento contra o dos agricultores (Guivant, 1997). Nesse sentido, as capacidades técnicas dos especialistas aprisionadas em caixas-pretas são uma forma de exercício do poder, o qual serve para impor uma "lei da

\footnotetext{
${ }^{20} \mathrm{O}$ manejo considerado inadequado das pastagens nativas refere-se principalmente ao sobrepastejo, que é um termo técnico utilizado para designar uma situação em que há excesso de animais por forragem (partes comestíveis das plantas) produzida (Santos et al., 2008).

${ }^{21}$ A expressão caixa-preta é utilizada por Latour (2000) para se referir à ciência "fechada" e "pronta", uma expressão da cibernética apropriada por Latour da cibernética que significa que um fato ou técnica científica se revela complexo demais, onde a seu respeito não é preciso saber nada, além do que nela entra e o que dela sai.

${ }^{22}$ Em relação às pesquisas universitárias, especialmente cabe destacar as realizadas na Universidade Federal do Rio Grande do Sul (UFRGS) e Universidade Federal de Santa Maria (UFSM). Quanto às empresas públicas de pesquisa, destacam-se a Empresa Brasileira de Pesquisa Agropecuária (EMBRAPA) e a Fundação Estadual de Estadual de Pesquisa Agropecuária (FEPAGRO).
} 
verdade", onde o objetivo é fazer o agricultor reconhecer e respeitar essa verdade. No entanto, o poder coloca em jogo relações entre indivíduos que são ao mesmo tempo receptores e emissores de poder (Foucault, 2011).

Portanto, apesar de os especialistas ocuparem posições privilegiadas para a construção do conhecimento técnico-científico e se utilizarem de dispositivos de poder ${ }^{23}$ para a legitimação desse conhecimento, o poder nem sempre é algo coercivo, que limita os espaços de escolhas dos agricultores. Muito pelo contrário, orientados por seus códigos morais e comportamentos culturais - ou repertórios culturais, como alude Ploeg (2008) -, os agricultores criam seus regimes de ação e reação contra as imposições colocadas de "cima para baixo" e, ao fazerem isso, os especialistas também sofrem os efeitos do poder provocados pelas estratégias reativas dos agricultores. Assim, mais do que se opor às formas de submissão e dominação, os agricultores afirmam seus direitos e asseguram a sua autonomia enquanto sujeitos produtores de conhecimento.

A partir das condições em que emergiram as novidades organizacionais do território Alto Camaquã, tratadas na seção anterior, iniciou-se um processo de geração do conhecimento dentro de uma perspectiva de "ciência no contexto do local", que tem suas bases epistemológicas e metodológicas assentadas nos princípios da agroecologia (Borba \& Trindade, 2009). Trata-se de um espaço construído deliberadamente dentro do projeto Alto Camaquã, o que tem suscitado a pesquisadores e técnicos a necessidade de novas abordagens epistemológicas e metodológicas no que se refere ao estudo da vegetação campestre.

Com isso, a "ciência no contexto do local" passou a promover "desvios de regras" no campo da produção do conhecimento sobre as formas de uso dos recursos naturais. Desse modo, os conhecimentos tácitos "escondidos" ou ignorados presentes nas práticas coprodutivas dos pecuaristas familiares em relação às estratégias de uso da vegetação campestre passaram a ter valor na produção de novos conhecimentos. Agentes de pesquisa e extensão rural e os pecuaristas começaram a estabelecer conjuntamente uma série de relações dentro de um espaço sociotécnico local ${ }^{24}$ visando à solução dos problemas acerca do manejo e do uso da vegetação campestre.

Assim, a partir da configuração desse espaço sociotécnico local, processos criativos de aprendizagem e geração de novos conhecimentos no que se refere ao estabelecimento de estratégias de uso da vegetação campestre têm emergido em um contexto de formação e fortalecimento de novos conhecimentos, envolvendo a ação coletiva de pesquisa, extensão e os próprios pecuaristas familiares. Desse modo, a própria concepção do que vem a ser um problema envolvendo a vegetação campestre não é mais atribuição exclusiva do conhecimento científico, onde o pesquisador tem um espaço privilegiado de domínio do conhecimento, mas a solução de problemas está acontecendo a partir do próprio local, tendo por base a interação entre conhecimentos científicos com conhecimentos tácitos.

Com isso, o aparente manejo "inadequado" da vegetação campestre exercido pelos pecuaristas familiares passou a ser visto não como um anacronismo do processo de desenvolvimento, mas como resultado de um processo particular representativo de uma condição camponesa. Tal condição representa a luta por autonomia dos camponeses como uma forma de construção e reprodução dos seus meios de vida em um contexto adverso, caracterizado por relações de dependência, marginalização e privação (Ploeg, 2008).

Essas constatações passaram a ser evidenciadas após a criação de UEPAs (Unidades Experimentais Participativas), as quais representam uma novidade tecnológica do Projeto Alto Camaquã e atualmente são o principal espaço sociotécnico de geração de novos conhecimentos a respeito da vegetação campestre. Assim, as UEPAs constituem um nó importante da

\footnotetext{
${ }^{23}$ Para Foucault (2011), dispositivo representa uma rede tecida por um conjunto de elementos heterogêneos (discursos, instituições, decisões regulamentares, leis, medidas administrativas, enunciados e práticas científicas, proposições filosóficas e morais), os quais definem processos de produção do saber, do poder e modos de subjetivação.

${ }^{24}$ Segundo Sabourin (2009), o espaço sociotécnico refere-se ao lugar e às circunstâncias que servem de suporte privilegiado para os encontros entre aqueles atores sociais que mantêm elos de proximidade de densidade suficiente para poder falar e realizar intercâmbios sobre assuntos e objetivos técnicos vinculados a seu trabalho.
} 
rede sociotécnica do Projeto Alto Camaquã, um "ponto de passagem obrigatório" que mobiliza e reúne atores humanos (pecuaristas, técnicos, pesquisadores) e não humanos (artefatos, plantas, solo, água, fauna do solo, etc.) que, juntos, de forma coletiva, são responsáveis pela geração de novos conhecimentos.

Se os pesquisadores, extensionistas e pecuaristas são capazes de "socializar" a vegetação campestre para estudá-la e lhe atribuírem importância, a vegetação campestre tem estabelecido grande capacidade de "naturalizar" esses atores sociais, mobilizando-os como seus porta-vozes. Ou seja, a vegetação campestre está permanentemente inserida nos discursos dos pesquisadores, extensionistas e pecuaristas, capazes de provocar e produzir novas ações e acontecimentos (e.g. dias de campo, relatórios, artigos) que têm modificado a história da produção do conhecimento a seu respeito. Como afirma Latour (2008), os não humanos são capazes de mobilizar e agir sobre o "mundo", não sendo possível entender a sociedade sem o recrutamento de não humanos socializados. Portanto, as ações e os resultados efetivamente produzidos nas UEPAs são eventos envolvendo ações de humanos e não humanos atuando em rede.

Através do espaço sociotécnico criado pelas UEPAs, revelou-se aos pesquisadores e extensionistas que as decisões que definem as práticas de manejo da vegetação campestre são orientadas por objetivos, interesses e experiências que os pecuaristas familiares recriam constantemente para desenvolver seus projetos de vida. Por disporem de áreas pequenas, se observa altas lotações de animais por área, as quais se justificam por um comportamento econômico específico. Ou seja, no calculus econômico dos pecuaristas, o maior número de animais no campo representa segurança frente às necessidades futuras do grupo familiar (Neske, 2009; Ribeiro, 2009).

De acordo com Ribeiro (2009), se dos pontos de vista técnico e produtivo as altas lotações caracterizam uma "irracionalidade" (pois menores lotações por área proporcionam maior produtividade), do ponto de vista da racionalidade dos pecuaristas familiares, o maior número de animais disponíveis é considerado como mercadoria de reserva. Portanto, segundo o autor, a racionalidade produtiva é estabelecer mais reservas por meio do gado e não de incrementar a produção e a produtividade.

No entanto, as altas lotações utilizadas como prática de manejo não isentam os animais de restrições alimentares, sobretudo no período de inverno, que corresponde à época mais crítica devido ao menor crescimento das pastagens naturais. É nesse período que frequentemente ocorrem óbitos de animais em razão da escassez de alimentos e/ou os pecuaristas se veem obrigados a vender animais para evitar futuras perdas. Em outras situações, devido às restrições de alimentos no inverno, os pecuaristas recorrem ao plantio de pequenas áreas de pastagens cultivadas $(0,5 \text { a } 2 \text { hectares })^{25}$.

Os pecuaristas reconhecem que a falta de controle da lotação de animais é uma prática que reduz a escassez de alimentos para os animais, principalmente no inverno. Nesse contexto, as UEPAs têm representado um espaço onde o conhecimento "válido" visando à solução dos problemas é o conhecimento construído na interface entre conhecimentos científicos e conhecimentos tácitos. Conforme Borba et al., (2009), é inconcebível promover novos conhecimentos e novas estratégias de manejo da vegetação campestre sem levar em consideração a experiência prévia dos pecuaristas familiares.

Assim, o foco não tem sido abordar os problemas relacionados com o manejo da vegetação campestre como um sistema isolado, mas procurar entendê-los dentro de um contexto mais amplo, considerando as práticas coprodutivas dos pecuaristas familiares previamente existentes que estão relacionadas com seus meios de vida. Por isso, a "ciência no contexto local" tem se constituído em um princípio fundamental pelos agentes do desenvolvimento da pesquisa e da extensão rural para o descobrimento de conhecimentos tácitos dos pecuaristas familiares.

Portanto, a contextualização local da ciência vem promovendo a interação dos conhecimentos de pesquisadores e extensionistas em uma situação de interface sociotécnica, onde sentidos a respeito dos conhecimentos gerados nas UEPAs são confrontados e negociados. No entanto, tais conhecimentos não têm sido excludentes,

\footnotetext{
${ }^{25}$ Ver Neske (2009) e Ribeiro (2009).
} 
pelo contrário, são preponderantemente complementares. Para os pecuaristas familiares, esses conhecimentos gerados passaram a fazer sentido ao seu repertório cultural, pois, eles próprios, também têm protagonizado a sua geração. O relato abaixo é de um pecuarista e evidencia a forma como os conhecimentos da "ciência no contexto local" têm sido incorporados em suas práticas cotidianas.

[...] todo mundo perdeu gado aqui na região. Eu tive vaca ganhando até $1 \mathrm{~kg}$ por dia [...] Depois que começamos a trabalhar juntos [se referindo ao trabalho na UEPA], tô mudando a maneira de ver o campo. Tem que permitir o campo rebrotar. Comecei a usar divisão de potreiro como reserva, e hoje penso em deixar reserva [de pasto] para cada estação [...] hoje tô usando a propriedade de acordo com a minha necessidade. (Pecuarista familiar)

O relato da entrevista evidencia que o pecuarista tem conseguido aliar mudanças na gestão do manejo da vegetação campestre de acordo com suas necessidades, sem com isso comprometer as estratégias que garantem a sua reprodução social e econômica. Assim, a modificação nas estratégias de manejo da vegetação campestre não tem como objetivo maior auferir ganhos econômicos, mas estabelecer um controle sobre a melhoria do processo de pastejo que seja apropriado pelos pecuaristas, visando à resolução dos problemas que enfrentam ou convivem cotidianamente, sobretudo a escassez de alimentação no inverno.

Do lado dos pesquisadores e técnicos, as UEPAs têm possibilitado uma revisão dos preceitos históricos de intervenção das organizações e, ao mesmo tempo, ampliam-se os horizontes para novos espaços de aprendizagem e mudanças de atitudes.

São 50 anos tentando fazer os pecuaristas mudarem de atitude, e eles não mudam!! Ai de repente tu cria uma unidade experimental participativa onde a partir da interação entre os pecuaristas familiares e os técnicos se exercitam coisas, se fazem reflexões, se formulam perguntas, se constroem respostas de maneira que isso faça sentido para os pecuaristas, e eles mudam de atitude. Isso é um aprendizado muito grande. Por quê? Nos ensina que existe um equívoco histórico por parte dos técnicos de querer impor modificações no sistema sem que elas façam sentido. (Pesquisador da Embrapa)

Esses relatos permitem constatar que a pesquisa participativa colocada como estratégia de aprendizagem tem assegurado a construção de novos conhecimentos anteriormente não existentes. Os conhecimentos individuais previamente existentes, ao interagirem conjuntamente, têm produzido efeitos e se constituído em saberes coletivos. O que promove o processo de aprendizagem é o fato de que perguntas e respostas vêm sendo formuladas e respondidas de forma coletiva, compondo uma intrincada composição entre conhecimentos tácitos e científicos, não havendo privilégio desses últimos em detrimento dos primeiros.

A partir das posições que os pesquisadores, os técnicos e os pecuaristas familiares ocupam no contexto das UEPAs, formam conhecimento sobre "si mesmos", constituindo a construção de diferentes modos de subjetivação ${ }^{26}$. Neste caso, a constituição das subjetividades humanas é agenciada pela natureza, pois a vegetação campestre, como principal "ator em cena", é que tem mobilizado os atores sociais ao seu redor. Esta reflexão, a partir da observação e do acompanhamento de todos os atores (ou actantes), leva a entender a emergência da produção de novidades para além da ação humana.

Conforme Latour (1997), a ontologia moderna é pautada pela divisão entre sociedade e natureza em zonas separadas, cabendo à ciência o papel de controle sobre a natureza. A rede sociotécnica relacionada ao Projeto Alto Camaquã parece que vai, aos poucos, contribuindo para o rompimento desta noção, antes tão presente entre a comunidade científica envolvida nos estudos da vegetação campestre.

São os agenciamentos de humanos e não humanos que têm criado as condições para a formação de novos enunciados ${ }^{27}$ que expressam um novo olhar e uma maior

\footnotetext{
${ }^{26}$ Foucault (1984) usa a expressão modos de subjetivação para se referir às práticas de constituição do sujeito.

${ }^{27}$ Para Foucault (2011), o enunciado é uma função de existência materializada como acontecimento e que pertence a certa formação discursiva. Ou seja, a noção de enunciado está relacionada a acontecimento e discurso.
} 
valorização dos recursos naturais do Alto Camaquã, possibilitando a construção de outra trajetória de produção do conhecimento. Portanto, o lugar de onde emergiram as novidades do Alto Camaquã é o próprio lugar.

\section{Considerações finais}

A produção de novidades representa um dispositivo heurístico que permite identificar práticas inovadoras, sendo, por isso, a expressão visível de "desvios de regras" dentro de um determinado regime sociotécnico dominante. Desse modo, as novidades retratadas ao longo desse trabalho fazem parte da própria trajetória do desenvolvimento no território Alto Camaquã. Isto porque, se de um lado, dentro de um curso histórico das últimas décadas, o território tem se legitimado por meio de discursos, narrativas e dispositivos normativos, de outro lado, é no próprio local que novos conhecimentos e experiências têm sido gerados, sendo potencialmente um ato de "contradesenvolvimento".

O projeto Alto Camaquã é uma novidade institucional que interliga outras novidades, as quais, no seu conjunto, possuem como princípio norteador a busca pela valorização e pela transformação de recursos historicamente "desprezados" em ativos capazes de gerar estratégias próprias e autônomas de desenvolvimento rural.

Assim, a produção de novidades do território Alto Camaquã tem emergido num contexto de valorização e combinação dos recursos e bens locais já existentes no território (cultura, relações sociais, recursos naturais, etc.). Porém, para que as ações de desenvolvimento sejam efetivas, permanentemente há o requerimento de uma nova base de conhecimentos, construídos com a participação coletiva de atores humanos em interação com os não humanos. $\mathrm{O}$ caso analisado nesse artigo evidencia a relação dos conhecimentos gerados e as práticas coprodutivas dos pecuaristas familiares no que tange às estratégias de uso e manejo da pastagem nativa.

Considera-se, então, que ao longo do tempo são os próprios pecuaristas familiares que têm desenvolvido respostas originais de adaptação e enfrentamento de problemas, usando, na maioria das vezes, unicamente os conhecimentos tácitos construídos pela prática $\mathrm{e}$ pela imersão em um contexto particular circundante. A identificação deste conhecimento levou à valorização da experiência acumulada pelos pecuaristas familiares e foi, justamente, este o ponto de partida para a construção de novidades, sendo o ambiente organizacional favorável nas empresas de pesquisa e extensão rural um importante primeiro passo. Neste sentido, o próprio arranjo inovador entre as organizações, uma vez construído contra os regramentos dominantes do regime modernizador, significa uma novidade.

O estabelecimento das UEPAs é uma novidade tecnológica do Projeto Alto Camaquã, pois elas representam um espaço sociotécnico onde diferentes conhecimentos (científicos e tácitos) se inter-relacionam e são transformados. No entanto, as UEPAs não revelam apenas as diferentes lógicas que orientam os regimes de ação de pesquisadores, técnicos e pecuaristas familiares; mais do que isso, favorecem interfaces que, aos poucos, vão permitindo a abertura da "caixa-preta" do regime sociotécnico e científico que retém o conhecimento a respeito da vegetação campestre. Nesse sentido, o Labeco, ocupando o lugar de ator-mundo, desempenha um papel importante na manutenção e no fortalecimento das novidades, bem como na continuidade das ações que, ainda que não passem exclusivamente por ele, dependerão em grande medida da sua capacidade de tradução.

A rede sociotécnica relacionada ao Projeto Alto Camaquã não é estática e novos atores humanos e não humanos estão constantemente se aproximando ou se afastando dela, o que pode redundar no surgimento de outras novidades, no desaparecimento ou no fortalecimento de algumas já existentes. Tais novidades no território Alto Camaquã têm gerado novas formas de cooperação, valorização dos recursos naturais e das identidades socioculturais. Ao serem construídas em oposição ao regime prevalente, as novidades no território são uma expressão de processos de resistência que podem estar promovendo "fissuras" no regime sociotécnico dominante. 


\section{Referências}

Abramovay, R. O capital social dos territórios: repensando o desenvolvimento rural. Economia Aplicada, São Paulo, v. 4, n. 2, p. 379-397, 2000.

Almeida, J. Da ideologia do progresso à ideia de desenvolvimento (rural) sustentável. In: ; Navarro, Z. (Org.).

Reconstruindo a agricultura: ideias e ideais na perspectiva do desenvolvimento rural sustentável. Porto Alegre: Editora UFRGS, 1997. p. 33-55.

Alonso, J. A. F. A persistência das desigualdades regionais no RS: velhos problemas, soluções convencionais e novas formulações. Indicadores Econômicos FEE, Porto Alegre, v.33, n.4, p. 101-114, 2006.

Altieri, M. A. Agroecologia: as bases científicas da agricultura sustentável. Rio de Janeiro: AS-PTA, 2002.

Arce, A.; Long, N. The Dynamics of Knowledge. Interfaces between Bureaucrats and Peasants. In: Long, N.; Long, A. (Org.). Battlefields of knowledge: the interlocking of theory and practice in social research and development. London and New York, 1992. p. 211-245.

Bandeira, P. S. As raízes históricas do declínio da Região Sul. In: Alonso, J. A. F.; Benetti, M. D.; Bandeira, P. S. Crescimento econômico da Região Sul do Rio Grande do Sul: causas e perspectivas. Porto Alegre: Fundação de Economia e Estatística - FEE, 1994. p. 7-48.

Boltanski, L.; Thévenot, L. The sociology of critical capacity. European Journal of Social Theory, London, 2(3), 359-377, 1999.

Borba, M. F. S. La marginalidad como potencial para la construccion de "outro" desarrollo: El caso de Santana da Boa Vista, Rio Grande do Sul, Brasil. 2002. 362 f. Córdoba, Tese (Doctorado em Sociologia, Agroecologia e Desenvolvimento Sustentável) - Instituto de Sociología y Estudios Campesinos, Universidad de Córdoba, 2002.

; Trindade, J. P. P. Desafios para conservação e a valorização da pecuária sustentável. In: Pillar, V. P. de; Müller, S. C.; Castilhos, Z. M. S. de; Jacques, A. V. Á. (Org.). Campos Sulinos: conservação e uso sustentável da biodiversidade. Brasília: Ministério do Meio Ambiente, 2009. p. 391-403.

; Boavista, L. R. Pesquisa participativa para estratégias de manejo sustentável dos recursos forrageiros dos campos naturais: pressupostos e aspectos metodológicos. Documentos. Bagé: Embrapa Pecuária Sul, 2009. et al. Ecologização da pecuária familiar na Serra do Sudeste. Documento Técnico. Bagé: Embrapa Pecuária Sul, 2009.

Callon, M. The Technology of an Actor-Network: The case of the Electric Vehicle. In: et al. (Org.). Mapping the Dynamics of Science and Technology: Sociology of Science in the Real World. London: The Macmillian, 1986. p. 19-34.

. A coperformação das ciências e da sociedade. Entrevista com Michel Callon. Política \& Sociedade, Florianópolis, v. 8, n. 14, p. 383-408, 2009.

Caporal, F. R.; Costabeber, J. A. Agroecologia e desenvolvimento rural sustentável: perspectivas para uma nova extensão rural. Agroecologia e Desenvolvimento Rural Sustentável, v. 1, n. 1, p. 16-37, 2000.

Costa Gomes, J. C.; Medeiros, C. A. B. Bases epistemológicas para a ação e pesquisa em Agroecologia: da ciência eficiente à ciência relevante. In: Souza, I. S. F.; Cabral, J. R. F. Ciência como instrumento de inclusão social. Brasília: EMBRAPA Informação Tecnológica, 2009. p. 249-275.

Favareto, A. S. Paradigmas do desenvolvimento rural em questão. São Paulo: Fapesp/Iglu, 2007.

Foucault, M. História da Sexualidade II: o uso dos prazeres. Rio de Janeiro: Graal, 1984.

. A arqueologia do saber. 5. ed. Rio de Janeiro: Forense Universitária, 1997.

. Microfísica do poder. 11. ed. Rio de Janeiro: Graal, 2011.

Fundação Estadual de Proteção Ambiental (FEPAM). Porto Alegre, 2009. Disponível em: <http://www.fepam.rs.gov.br/ qualidade/bacia_camaqua.asp $>$. Acesso em: 11/04/2014.

Gazolla, M. Conhecimentos, produção de novidades e ações institucionais: cadeias curtas das agroindústrias familiares. 292 f. Porto Alegre, Tese (Doutorado em Desenvolvimento Rural) - Faculdade de Ciências Econômicas, Universidade Federal do Rio Grande do Sul, 2012.

Geels, F. W. Understanding System Innovations: a Critical Literature review and a Conceptual Synthesis. In: Elzen, B.; Geels, F. W.; Green, K. System Innovation and the Transition to Sustainability: theory, evidence and policy. Cheltenham, Northampton: Edward Elgar, 2004. p. 19-47.

Gliessman, S. R. Agroecologia: processos ecológicos em agricultura sustentável. Porto Alegre: Editora UFRGS, 2000. 
Guivant, J. S. Heterogeneidade de conhecimentos no desenvolvimento rural sustentável. Cadernos de Ciência e Tecnologia, Brasília: Embrapa, v. 14, n. 3, 411-448, set./dez., 1997.

Hayami, Y.; Ruttan, V. W. Desenvolvimento Agrícola: teoria e experiências internacionais. Brasília: Embrapa, 1988.

Instituto Brasileiro de Geografia e Estatística (IBGE). Censo Agropecuário. 2006. Rio de Janeiro: IBGE, 2006. IBGE, 2011.

. Produção Agrícola Municipal. 2011. Rio de Janeiro:

Kemp, R.; Schot, J.; Hoogma, R. Regime Shifts to Sustainability through Processes of Niche Formation: the Approach of Strategic Niche Management. Technology Analysis \& Strategic Management, v. 10, n.2, 175-196, 1998.

Latour, B. Jamais fomos modernos. São Paulo: Editora 34, 1997.

. Ciência em ação. São Paulo: Editora da Unesp, 2000.

. A esperança de pandora: ensaios sobre a realidade dos estudos científicos. Bauru: EDUSC, 2001.

Políticas da natureza: como fazer ciência na natureza. Bauru: EDUSC, 2004.

Reensamblar lo social: una introducción a la teoria del actor-rede. Buenos Aires: Manantial, 2008.

Long, N. Introdução à sociologia do desenvolvimento rural. Rio de Janeiro: Zahar, 1982.

Sociología del desarrollo: una perspectiva centrada en el actor. México: Centro de Investigaciones y Estudios Superiores en Antropología Social, 2007.

; Ploeg, J. D. van der. Heterogeneidade, ator e estrutura: para a reconstituição do conceito de estrutura. In: Schneider, S.; Gazolla, M. Os atores do desenvolvimento rural: perspectivas teóricas e práticas sociais. Porto Alegre: Editora UFRGS, 2011. p. 21-48.

Marques, F. C. Velhos conhecimentos, novos desenvolvimentos - transições no regime sociotécnico da agricultura: a produção de novidades entre agricultores produtores de plantas medicinais no Sul do Brasil. 220 f. Porto Alegre, Tese (Doutorado em Desenvolvimento Rural) - Faculdade de Ciências Econômicas, Universidade Federal do Rio Grande do Sul, 2009.

. Nicho e novidade: nuanças de uma possível radicalização inovadora na agricultura. In: Schneider, S.; Gazolla, M. (Org.). Os atores do desenvolvimento rural: perspectivas teóricas e práticas sociais. Porto Alegre: Editora UFRGS, 2011. p. 189-204.
Matte, A. Vulnerabilidade, capacitações e meios de vida dos pecuaristas de corte da Campanha Meridional e Serra do Sudeste do Rio Grande do Sul. 186 f. Dissertação (Mestrado em Desenvolvimento Rural) - Faculdade de Ciências Econômicas, Universidade Federal de Rio Grande do sul, Porto Alegre, 2013.

Mello, A. M. de. Sementes que brotam da crise: a produção de novidades organizacionais na agricultura familiar do oeste de Santa Catarina. 298 f. Tese (Doutorado em Desenvolvimento Rural) - Faculdade de Ciências Econômicas, Universidade Federal do Rio Grande do Sul, Porto Alegre, 2009.

Ministério do Meio Ambiente (MMA). Bioma Pampa. 2010. Disponível em: <http://www.mma.gov.br/biomas/pampa>. Acesso em: 10/08/2013.

Moors, E.; Rip, A.; Wiskerke, J. The Dynamics of Innovation: a Multilevel Mo-evolutionary Perspective. In: Wiskerke, J. S. C.; Ploeg, J. D. van der. Seeds of Transition. Assen: Royal van Gorcum, 2004. p. 31-56.

Neske, M. Z. Estilos de agricultura e dinâmicas locais de desenvolvimento rural: o caso da pecuária familiar no território Alto Camaquã do Rio Grande do Sul. 207 f. Dissertação (Mestrado em Desenvolvimento Rural) - Faculdade de Ciências Econômicas, Universidade Federal do Rio Grande do Sul, Porto Alegre, 2009.

; Miguel, L. A. de; Borba, M. F. S. Capital ecológico e a construção de autonomia na produção familiar: o caso da pecuária familiar do Rio Grande do Sul. Cadernos de Ciência \& Tecnologia, Brasília, v, 29, n.1, 291-317, 2012.

; Almeida. J.; Radomsky, G. F. W. Reinterpretando o desenvolvimento rural em "zonas marginalizadas" no sul do Brasil: a contribuição dos estudos pós-coloniais. Revista de Ciencias Sociales, v. 26, n. 32, 93-113, 2013.

Neves, D. P. Mediação social e mediadores políticos. In: Neves, D. P. (Org.). Desenvolvimento social e mediadores politicos. Porto Alegre: Editora UFRGS, 2008, p. 21- 44.

Oliveira, D.; Gazolla, M.; Schneider, S. Produzindo novidades na agricultura familiar: agregação de valor e agroecologia para o desenvolvimento rural. Cadernos de Ciência \& Tecnologia, Brasília, v. 28, n.1, p. 17-49, 2011a.

; _ _ _ Carvalho, C. X.; Schneider, S. A produção de novidades: como os agricultores fazem para fazer diferente? In: Schneider, S.; Gazolla, M. (Org.). Os atores do desenvolvimento rural: perspectivas teóricas e práticas sociais. Porto Alegre: Editora UFRGS, 2011b. p. 91-115.

Oostindie, H.; Broekhuizen, R. von. The Dinamic of Novelty Production. In: Ploeg, J. D. van der; Marsden, T. (Org.) Un- 
folding Webs: The Dynamics of Regional Rural Development. Assen: Royal van Gorcum, 2008. p. 68 - 86.

Ploeg, J. D. van Der. Camponeses e impérios alimentares. Porto Alegre: Editora UFRGS, 2008.

et al. Rural Development: From Practices and Policies towards Theory. Sociologia Ruralis, Malden, 40(4), 391-408, 2000.

et al. On Regimes, Novelties, Niches and Co-Production. In: Wiskerke, J. S. C.; Ploeg, J. D. van der. Seeds of Transition. Assen: Royal van Gorcum, 2004. p. 1-30.

Ribeiro, C. M. Estudo do modo de vida dos pecuaristas familiares da região da Campanha do Rio Grande do Sul. $304 \mathrm{f}$. Tese (Doutorado em Desenvolvimento Rural) - Faculdade de Ciências Econômicas, Universidade Federal do Rio Grande do Sul, Porto Alegre, 2009.

Rocha, J. M. As raízes da crise da Metade Sul: estudo da formação econômica do Rio Grande do Sul. Bagé: Fundação Universidade Federal do Pampa, 2011.

Rostow, W. W. Etapas do desenvolvimento econômico: um manifesto não comunista. Rio de Janeiro: Zahar, 1974.

Sabourin, E. Camponeses do Brasil: entre a troca mercantil e a reciprocidade. Rio de Janeiro: Garamond, 2009.

Santos, S. A. et al. Guia para estimativa da taxa de lotação em pastagens naturais do pantanal. Corumbá: Embrapa Pantanal, 2008.

Saquet, Marcos. Abordagens e concepções de território. São Paulo: Expressão Popular, 2007.
Sardan, J. P. O. de. Anthropologie e Développement: essai en Socio-Anthropologie du Changement Social. Paris: APAD-Karthala, 1995.

Schmitt, C.; Grisa, C. Agroecologia, mercados e políticas públicas: uma análise a partir dos instrumentos de ação governamental. In: Niederle, P. A.; Almeida, L. de; Vezzani, F. M. (Org.). Agroecologia: práticas, mercados e políticas para uma nova agricultura. Curitiba: Kairós, 2013. p. 215-265.

Schneider, S. Ciências sociais, ruralidade e territórios: em busca de novas referências para pensar o desenvolvimento. Campo e Território, Uberlândia, 4, 24-62, 2009.

Schultz, T. W. A transformação da agricultura tradicional. Rio de Janeiro: Zahar, 1965.

Scott, J. C. Weapons of the Weak: Everyday Forms of Peasant Resistence. Yale: Yake University Press, 1987.

Sevilla-Guzmán, E. Perspectivas agroecológicas. Córdoba: Universidad de Córdoba, 2006.

Thomas, A. Development as Practice in a Liberal Capitalist World. Journal of International Development, Hoboken, 12, 773-787, 2000.

Trindade, J. P.; Borba, M. F. S.; Lefevbre, J. Território do Alto Camaquã. Apresentação da cobertura vegetal do Alto Camaquã. Documentos. Bagé: Embrapa Pecuária Sul, 2010.

Ventura, F.; Milone, P. Novelty as Redefinition of Farm Boundaries. In: Ploeg, J. D. van der; Wiskerke, J. S. C. (Org.) Seeds of Transition: essays on Novelty Production, Niches and Regimes in Agriculture. Assen: Royal Van Gorcum, 2004. p. 57-92. 